\title{
Linn da Quebrada e os engajamentos performativos com as mídias digitais: uma análise sociológica de uma trajetória artística dissidente de gênero
}

\author{
Patrick Borges Ramires de Souza' (iD) 0000-0002-2414-8056 \\ Fernando de Figueiredo Balieiro2 (iD) 0000-0003-3952-4779 \\ 'Universidade Estadual de Campinas, Programa de Pós-Graduação em Ciências \\ Sociais, Campinas, SP, Brasil. 13083-970 - soniabia@unicamp.br \\ ${ }^{2}$ Universidade Federal de Santa Maria (UFSM), Santa Maria, RS, Brasil. \\ 97105-900 - ppg.mestrado.ufsm@gmail.com
}

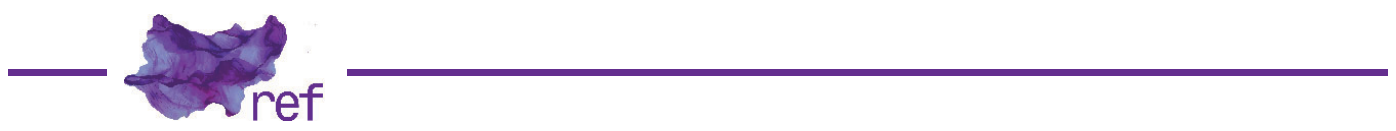

\begin{abstract}
Resumo: No artigo, analisamos o uso das mídias digitais por Linn da Quebrada, artista dissidente em termos de gênero, sexualidade, raça e classe social. Linn se identifica enquanto bixa, preta, ora travesti, ora transexual e "da quebrada", tendo conquistado certa visibilidade midiática a partir da publicação de produções audiovisuais no YouTube. A abordagem metodológica consistiu em etnografia digital por perambulação, na qual percorremos os fluxos de relações constituídas pela artista a partir do uso do YouTube, nos anos de 2016 e 2017, visando refletir sobre os engajamentos performativos que ela adotou em plataformas digitais. Também demonstramos como a emergência da artista se dá a partir da problematização das normas de gênero e sexualidade, em momento de acirramento do debate político sobre essas mesmas no país e da consolidação de uma configuração midiática altamente segmentada em uma sociedade digital.
\end{abstract}

Palavras-chave: Linn da Quebrada; engajamentos performativos; mídias digitais; gênero; sexualidade.

Linn da Quebrada and The Performative Engagements with Digital Media: A Sociological Analysis of a Gender Dissident Artistic Trajectory

Abstract: The article analyzes the use of digital media by Linn da Quebrada, a dissident artist in terms of gender, sexuality, race and social class. Linn identifies herself as "bixa", black, sometimes transvestite, sometimes transsexual and "da quebrada", having gained some media visibility from the publication of audiovisual productions on YouTube. The methodological approach consisted of wandering digital ethnography, in which we walked through the relationship flows created by the artist from the use of YouTube, in 2016 and 2017, in order to reflect on the performative engagements, she adopted on digital platforms. We also demonstrate how the emergence of the artist comes from the problematization of gender and sexuality norms, at the moment of intensifying the political debate about them in the country and the consolidation of a highly segmented media configuration in a digital society.

Keywords: Linn da Quebrada; Performative Engagements; Digital Media; Gender; Sexuality.

\section{Introdução}

Com uma linguagem que aciona diretamente a ouvinte/espectadora e com a sonoridade e poesia do funk, Linn da Quebrada fala, em suas músicas, sobre sexo, desejo, discrição e in/ visibilidade das bixas, das travestis negras da periferia de São Paulo/SP. Com 28 anos e formada em teatro pela Escola Livre de Teatro de Santo André, moradora da Zona Leste de São Paulo, 
a artista angariou popularidade a partir de sua presença em plataformas de mídias digitais, primeiramente, com a publicação do videoclipe de "Enviadescer" (LINN DA QUEBRADA, 2016), no YouTube, no ano de 2016, e, em seguida, pelos engajamentos performativos que realizou com o uso dessa e de outras plataformas de mídias digitais, tais quais o Facebook e o Instagram.

Como "engajamento performativo", entendemos o modo como Linn da Quebrada se constitui enquanto artista por meio das plataformas digitais, considerando as últimas como mediadoras e não vetores neutros (José VAN DIJCK, 2016), nas quais a artista veicula seu trabalho, além de, por elas, também publicar imagens e vídeos. A noção de engajamento performativo ressalta a ação criativa de Linn com as mídias, configurada no modo como ela explora seu corpo, suas histórias de vida e suas experiências enquanto sujeito dissidente das normas de gênero, em diferentes canais do YouTube, Instagram e programas de televisão. Esses engajamentos buscam compreender, portanto, a produção do gênero enquanto performativo (Judith BUTLER, 2017), um fazer que se dá pela prática de Linn, pela relação que ela constitui com seus públicos, e pelas configurações das próprias mídias, as quais, dialogicamente, também produzem Linn.

Utilizamos o conceito de dissidência de gênero em contraste à "diversidade de gênero", entendendo que a última recai em abordagem normalizante, materializada no ideal de "respeito pela tolerância". Na perspectiva de Leandro Colling (2018), "diversidade" ignora o modo como são produzidas as hierarquias que constituem as normas de gênero e sexualidade. A noção de dissidência atenta para performatividades de gênero que buscam questionar o modo como a heternormatividade permeia as relações sociais nas sociedades contemporâneas, incluindo os sujeitos que não se identificam enquanto heterossexuais, bem como a forma na qual ela se articula a outros modos de hierarquização social, em especial, em suas dimensões raciais e de classe social.

Autoidentificada como "bixa, preta, trans e periférica", Linn da Quebrada não é a primeira artista, contudo, a ganhar notoriedade ao ter a dissidência de gênero como cerne de suas performances. Muito antes dela, a figura de Ney Matogrosso foi emblemática na passagem dos anos 1960 aos 1970 no Brasil, a partir do uso de elementos como a sensualidade, o exotismo e a feminilidade expressa em um corpo masculino no período de ditadura civil militar (Flávio QUEIROZ, 2009). Ao lado da ampla veiculação midiática de suas performances, o grupo Dzi Croquettes também se fez reconhecido no cenário cultural nacional e internacional, no mesmo contexto, questionando padrões rígidos de gênero, materializados em estéticas andróginas, contestando o regime político e os códigos de gênero e sexualidade do período. Ainda é digno de menção o caso dos "Shows de Travestis", entre as décadas de 1960 a 1980, na cidade do Rio de Janeiro, e que tinham como protagonistas as transformistas Rogéria, Divina Valéria, Marquesa, Yeda Brown, Susy Parker e Jane Di Castro, as quais ganharam notoriedade com suas performances, e que chegaram a alcançar os meios de comunicação de massa, por meio da televisão (Thiago SOLIVA, 2018).

O que possuem em comum é a relação aproximada com as mídias analógicas ao construírem certa projeção de suas performances. Essas mídias que, na década de 1970, estavam baseadas na centralidade da televisão e na presença importante do rádio ou dos jornais impressos, passam, no século XXI, a competir ou a se mesclar com as tecnologias informacionais disponíveis na era digital, quando uma nova configuração midiática dá espaço para a emergência de tantas performances que podem ser pensadas como subversão de gênero (BUTLER, 2017), como o é a construção performativa da artista Linn da Quebrada. A contestação dissidente de Linn se constitui, inclusive, em contraste com a visibilidade conquistada pelas travestis na aludida década. Rogéria ${ }^{1}$ fazia questão de diferenciar suas performances da percepção pública de "travestis estereotipadas", associadas à vulgaridade e à prostituição (SOLIVA, 2018, p. 34). Linn da Quebrada, ao contrário, enaltece variadas formas de experiências da travestilidade e transexualidade, evitando hierarquizações moralizantes em relação às mesmas.

Linn compõe uma nova geração de produção artística, na qual performances dão destaque ao corpo, à sensualidade, à sexualidade e à dissidência de gênero, além de, em seu caso, a identificação com as classes populares e com ênfase na identidade racial, ao se autodenominar "preta". Podemos destacar artistas como Liniker, da banda "Liniker e os Caramelos", Assucena Assucena e Raquel Virgínia, do grupo musical "As Bahias e a Cozinha Mineira", as drag queens Pabllo Vittar e Glória Groove, a MC Xuxu e a MC Trans e o rapper Rico Dalasam - dentre muitas outras artistas atuais que usam do tensionamento com as normas de gênero como mote para seu fazer artístico. Muitas delas, para além de suas produções audiovisuais individuais, produzem conjuntamente, inclusive para conseguirem financiamentos coletivos para arcar com as despesas das suas produções audiovisuais (Patrick SOUZA, 2019).

Divulgadas no YouTube, Facebook e Instagram, essas produções passam a fazer parte do cotidiano de ampla audiência, cujo consumo não se restringe somente ao entretenimento. Elas estão associadas a demandas contemporâneas de reconhecimento das diferenças em relação

'Rogéria foi atriz, cantora, maquiadora e transformista brasileira, e que dizia ser "a travesti da família brasileira". 
a normas presumidas calcadas em gênero, sexualidade, classe e "raça". Ou seja, um grupo de artistas que atinge suas audiências a partir de um modo de comunicação que envolve o compartilhamento de experiências de identificações dissidentes enquanto travestis, transexuais, não binárias e que falam, em sua grande maioria, reforçando sua localização social e política da periferia de grandes centros urbanos. ${ }^{2}$

Partimos da compreensão de que as mídias digitais trazem formas de comunicação radicalmente interativas em relação a mídias analógicas que as precederam, caracterizando-se por uma forma de comunicação multimodal que perpassa variadas plataformas e também pela presença de uma audiência ativa que faz com que a produção de significado seja complexa, em uma lógica de rede, ainda que assimétrica, com fluxos e contrafluxos comunicacionais caracterizados pela descentralização e pulverização, tal como abordado por Manuel Castells (2015).

Considerando que essa gama de artistas se utiliza das mais variadas mídias digitais para se comunicar e divulgar suas produções audiovisuais, propomo-nos a perambular por elas para compreender o que esses usos nos informam sobre características contemporâneas desse universo de emergência de diferentes performatividades de gênero dissidentes nestas produções musicais e audiovisuais. Focaremos nos usos que a artista Linn da Quebrada faz das mídias sociais, com atenção especial ao YouTube, plataforma na qual passou a construir um engajamento performativo com as mídias digitais, a partir do qual adquiriu audiência crescente em um continuum on-offline. Não nos furtaremos de uma perspectiva crítica em relação aos limites da contestação nos termos propostos pela artista. Reconhecemos tanto o caráter comercial das plataformas, bem como que a projeção da artista se faz dentro de uma sociedade cada vez mais segmentada e, portanto, para um público delimitado.

Ao focarmos nas mídias digitais, recusamos uma leitura que atribui à carreira ascendente de Linn única e exclusivamente os seus usos das mesmas. Argumentamos que há transformações substanciais que compõem o contexto da trajetória da artista. Decorrente de demandas de movimentos sociais e seu progressivo reconhecimento institucional nas décadas que a precederam, sua carreira é tributária de um novo regime de visibilidade em relação a diferenças de gênero e sexualidade que, conforme iremos expor, encontra-se em uma batalha diante de uma cruzada moral que se estabeleceu nos últimos anos em contraposição aos direitos sexuais e reprodutivos. As últimas décadas foram marcadas por demandas de reconhecimento diversas que se fizeram presentes tanto na produção artística como na geração de conhecimento acadêmico. Dentre elas, a emergência de ativismos trans e também negro, com destaque para os feminismos negros que partem da necessidade de abordar de forma conjunta as dimensões de gênero e de raça na apreensão e contestação das relações sociais hierárquicas.

Para a abordagem de como as questões de gênero, sexualidade e raça se encontram imbricadas na trajetória da artista, partimos da concepção de interseccionalidade, tal como abordada por Avtar Brah (2006). Nos termos da autora, "estruturas de classe, racismo, gênero e sexualidade não podem ser tratadas como 'variáveis independentes' porque a opressão de cada uma está inscrita dentro da outra - é constituída pela outra e é constitutiva dela" (BRAH, 2006, p. 351). As dimensões de classe, gênero, sexualidade e raça e suas intersecções são abordadas a partir de como os elementos aparecem contextualmente, no material empírico em análise. O conceito de interseccionalidade fora utilizado em outros trabalhos que abordaram aspectos artísticos e políticos da produção de Linn da Quebrada, como o fizeram Colling, Alexandre Souza e Francisco Sena (2017). Aqui ele é recuperado para a análise de sua performatividade com ênfase nos seus usos das mídias digitais.

Empreendemos uma etnografia digital por perambulação (Débora LEITÃO; Laura GOMES, 2017), que consistiu em perambular pelos fluxos das relações constituídas pela artista Linn da Quebrada, com foco específico no YouTube, em vídeos de diferentes canais nos quais ela se apresentou enquanto artista, para uma audiência diversificada. A perambulação, na perspectiva das antropólogas Débora Leitão e Laura Graziela Gomes (2018), envolve seguir os fluxos dos usos das diferentes plataformas de mídias digitais em ambientes de rápida e intensa circulação de conteúdo, observando aspectos específicos de uma socialidade que se desenvolve em plataformas digitais marcadas por uma topografia e ritmos particulares. Tal metodologia foi pensada em analogia com uma perspectiva da sociologia urbana voltada ao estudo das socialidades efêmeras e fugidias das grandes cidades, retomando a figura do flâneur, em seu movimento transitório e efêmero, proporcionando

uma sensibilidade etnográfica transeunte, de idas e vindas, percorrendo caminhos em meio à multidão de imagens e mensagens, [que] pode ser profícua quando acionada na observação de plataformas que têm como característica os trânsitos intensos e a efemeridade (LEITÃO; GOMES, 2017, p. 45-46).

\footnotetext{
2 Optamos pelo uso de identificação, em vez de identidade, para ressaltar a forma processual de construção identitária.
} 
Este artigo é derivado de uma dissertação de mestrado (SOUZA, 2019) que se baseou nesta metodologia, seguindo fluxos de hashtags e stories, com especial atenção para as relações produzidas a partir do conjunto de interações possibilitadas pelos usos da plataforma do Instagram, seguindo o perfil de Linn da Quebrada. Para nossos objetivos delimitados aqui, abordaremos Linn da Quebrada a partir de suas aparições em diversas mídias, compreendendo uma análise de uma artista na era da convergência midiática, na qual as mídias analógicas, ante a emergência das chamadas novas mídias, não perdem sua importância; antes, observase a intensificação da presença midiática na vida social (Richard MISKOLCI; Fernando BALIEIRO, 2018).

Dividimos o texto em quatro momentos: no primeiro, demonstramos quem é Linn da Quebrada, de modo a evidenciar a trajetória na qual emerge enquanto artista e o destaque que angaria no YouTube; no segundo momento, abordamos sua circulação na mesma plataforma, para além de seu canal, na análise de sua entrevista para a apresentadora Regina Volpato (2016); em terceiro, a contextualizamos no cenário de disputa sobre questões envolvendo gênero e sexualidade e destacamos os fluxos do consumo de Linn em um continuum on-offline. Por último, abordando a convergência entre as plataformas digitais e a televisão, enfocamos sua participação em um programa televisivo, "Amor e Sexo", da TV Globo (GLOBOPLAY, 2017).

\section{Linn da Quebrada: do YouTube à premiação e turnê internacional}

Sou Linn da Quebrada, artista multimídia, cantora, performer, terrorista de gênero, nem ator nem atriz, atroz. Eu sempre enxerguei o funk como a poesia da quebrada. Eu acho que não é privilégio do funk ser um espaço machista, um espaço de exclusão. Há muitas outras vertentes musicais com um machismo dissimulado, néh, e onde a gente às vezes não consegue enxergar sua violência, como a violência é sutil. A arte como um todo, eu sinto que nunca foi um espaço receptivo a mim, assim como nenhum outro espaço é receptivo a corpos estranhos, e corpos estranhos como o meu. Eu tô problematizando pra encontrar solução, néh? [...] (NEXO JORNAL, 2018, grifos nossos).

Em maio de 2016, Linn da Quebrada estreou com sua primeira produção audiovisual, denominada "Enviadescer", publicada no YouTube (2016). O videoclipe apresenta uma sequência de imagens dinâmicas, e a periferia compõe o centro tanto da narrativa quanto da estética do audiovisual, ao mesmo tempo em que o funk constitui sua sonoridade. Na performance do videoclipe, ao lado dela, são apresentados dançarinos e dançarinas negras que afirmam a negritude com seu penteado afro, bixas efeminadas com estética afrontosa, além das vestimentas populares, em corporalidades que fogem aos padrões midiáticos de magreza e em movimentos que reforçam uma sensualidade própria do funk, com o destaque para a centralidade que Linn ocupa nas câmeras. Tal apresentação sinaliza a perspectiva transgressora da artista que visa, com sua arte, tensionar as normas excludentes e discriminatórias da sociedade em que vive.

De forma provocativa, Linn começa a música com "Ei, psiu, você aí, macho discreto, Chega mais, cola, aqui, vamo bater um papo reto, que eu não tô interessada no seu grande pau ereto". Em uma linguagem marcada pela presença do vocabulário sexual explícito, a letra alude a uma crítica à heteronormatividade e, em específico, à reprodução de uma masculinidade que simula a hegemônica, ao aludir ao "macho discreto", recorrência explícita nos aplicativos de busca afetiva e sexual entre homens, que demarca sua oposição e rechaço aos efeminados.

Nas letras e nos corpos representados problematiza-se a suposta ordem natural da matriz heterossexual de gênero (BUTLER, 2017), calcada na coerência socialmente imposta entre sexo - gênero - desejos - práticas sexuais, produzindo dissidências de gênero e sexualidade. Ao se apresentar como "bixa" e "travesti", Linn busca ressaltar a diferença, em suas tensões com as normas, em vez de reforçar uma identidade fixa. Além disso, recusa uma representação de si a partir de uma imagem higienista da diferença, ao privilegiar cenários e corpos que rompem com padrões estéticos com conotações hegemônicas de classe e "raça".

Linn passou grande parte de sua infância e adolescência nas cidades de Votuporanga e São José do Rio Preto, ambas no interior do estado de São Paulo, na companhia de uma tia. Foi testemunha de Jeová, educada em família religiosa, tendo rompido com a tradição familiar após passar a se identificar enquanto gay e, posteriormente, afirmar-se enquanto travesti.

A trajetória dela nos permite perceber questões que, unindo religião, sexualidade e gênero, aparecerão de forma crítica na produção da própria performance da artista. Após se mudar para a capital, incorporou esses temas nas suas produções artísticas. Inicialmente, sua atuação esteve voltada para a arte na rua, por meio do Coletive Friccional, do qual fez parte. Nesse coletivo, atuou em diferentes performances, com destaque para "DPósito" e "Contar os Corpos e Sorrir". De sua experiência dissidente das normas de gênero e de sexualidade, assim como de seu contato com o teatro, Linn incorporou questionamentos sociais e políticos em futuras produções audiovisuais. 
Em fevereiro de 2018, Linn estreou sua primeira turnê internacional (Trava Tour), ${ }^{3}$ com o lançamento do primeiro disco, intitulado "Pajubá", ${ }^{4}$ gravado em 2017 e fruto de financiamento coletivo criado a partir da plataforma Kikante de financiamentos on-line. A turnê acompanhou a participação da artista no Festival de Cinema da Alemanha, no lançamento do filme "Bixa Travesty", dirigido por Kiko Goifman e Claudia Priscila. Nele, são narrados momentos da trajetória dela junto aos palcos e da cena da música trans de São Paulo, entre os anos de 2016 a 2017. O filme saiu vencedor na categoria Teddy Awards, dedicado à temática LGBTQ. O intervalo de maio de 2016 a fevereiro de 2018 marca o curto período no qual a artista lançou sua primeira produção audiovisual no YouTube e tornou-se premiada internacionalmente em filme sobre sua curta trajetória artística.

A turnê marcou um momento ascendente na carreira da artista, assim como deu outro significado ao lugar comum ocupado por travestis no ingresso em território europeu, a partir do mercado do sexo e da prostituição, ou então em busca de modificações corporais (Flávia TEIXEIRA, 2008; Larissa PELÚCIO, 2005; 2009; 201 1a; 201 1b; Jorge LEITE JUNIOR, 2008; 2014; Maria Cecília PATRICIO, 2009). Linn chegou a partir de seu reconhecimento artístico, participando do festival alemão em momento posterior a seu álbum de estreia, "Pajubá".

No Brasil, ela já havia atuado no filme "Meu corpo é Político", lançado em novembro de 2017 e dirigido por Alice Riff, que apresenta a trajetória de quatro pessoas trans em São Paulo, e também compôs o elenco do filme "Corpo Elétrico", lançado em agosto de 2017, e que contou com direção de Marcelo Caetano e William Lifestyle. Nessas produções, Linn da Quebrada aparece como atriz e cantora, demarcando sua intenção política de dar visibilidade a corpos de travestis pretas de periferia urbana, com os quais se identifica.

A visibilidade alcançada por Linn, quando participou dos circuitos fílmicos ou de produção de turnê internacional, foi amplificada a partir dos engajamentos digitais com sua audiência. O trabalho enquanto performer de palco é intercalado com sua presença digital, em um novo contexto em que relações são produzidas e alimentadas a partir das interações da artista com a audiência. Seu público a acompanhou por meio de publicações de "resumos" da turnê em forma de vídeos no YouTube, e de takes do cotidiano de suas experiências, especialmente a partir da ferramenta stories do Instagram.

Nancy Baym (2018) explora como uma nova configuração na relação entre artistas e audiências se instaurou com a emergência de uma sociedade cada vez mais mediada pelas plataformas digitais. A passagem da produção musical para uma economia digital, portanto, não ocorreu sem sua reconfiguração. Por um lado, destaca uma aparente autonomia de artistas em relação às gravadoras, se comparadas ao período pré-internet e, de outro lado, descreve como os artistas, especialmente aqueles que não alcançam o mainstream, passaram, cada vez mais, a depender da própria gestão da carreira on-line. Tal gestão se realiza, desde meados dos anos 2000 , com a mediação das plataformas digitais que, por sua vez, demandam presença ubíqua dos mesmos, rompendo antigas divisões entre público e privado. Trata-se de uma nova economia relacional que, como no caso de Linn, significou intercalar a divulgação de sua carreira com a exposição frequente de sua vida privada.

Pelo Instagram, a artista publica suas imagens, vídeos de curta duração e interage com quem "segue" seu perfil, como também alimenta a expectativa do público, que demanda conhecer sua intimidade e seu cotidiano. Por meio dessas plataformas, Linn constrói uma apresentação de si que conjuga o pertencimento à periferia à dissidência de gênero, além da afirmação de sua identidade racial. Em suas narrativas digitais, Linn aparece como um corpo ora dissidente, mas, conforme mostraremos, também "negocia" a dissidência em suas aparições midiáticas para um público mais abrangente.

\section{A dissidência negociada na convergência midiática}

Voltamos aos engajamentos performativos com as mídias digitais de Linn da Quebrada, a partir dos quais, progressivamente, ocupou outros espaços midiáticos e off-line. Isso em razão de que essas mídias não são somente ferramentas disponíveis em um espaço "virtual". Ao contrário, a utilização das plataformas digitais, antes limitadas a suas produções teatrais de rua, tanto acompanha o desenvolvimento da carreira da artista, como a modifica.

Conforme argumenta o sociólogo Richard Miskolci (2017), digital

[...] não é uma definição técnica, mas uma caracterização de nosso mundo como marcado pela conexão por meio de tecnologias comunicacionais contemporâneas que se definem cotidianamente como digitais e que envolvem o suporte material de equipamentos como notebooks, tablets e smartphones, bem como diferentes tipos de redes de acesso, conteúdos

\footnotetext{
${ }^{3}$ Iniciada em fevereiro daquele ano, percorreu países como Alemanha, Suíça, França e Portugal. Foi a primeira das cinco turnês internacionais de Linn da Quebrada ao longo do ano de 2018.

${ }^{4}$ Linguagem específica utilizada entre as travestis para se comunicar, e que utiliza uma série de termos oriundos do ioruba-nagô, compondo uma série de gírias conhecida como "bajubá" ou "bate-papo".
} 
compartilháveis e, por fim, mas não por menos, plataformas de conectividade. Em termos sociológicos, o que define a nossa era é a conexão em rede por meios comunicacionais tecnológicos. Digital, portanto, se opõe ao analógico, enfatizando o aprimoramento tecnológico, enquanto a conexão em rede por meio de plataformas enfatiza a maneira como se constroem relações sociais (p. 23).

A utilização das mídias digitais por Linn da Quebrada acompanha um processo recente de ampliação do acesso à internet no Brasil. A Pesquisa Nacional por Amostra de Domicílio, realizada pelo Instituto Brasileiro de Geografia e Estatística (IBGE, 2015; 2016; 2017), demonstra que aproximadamente $70,5 \%$ da população brasileira obtiveram acesso à internet no ano de 2017, o que representa um aumento significativo em relação a pesquisas realizadas em 2016, ano em que o percentual foi de $63,6 \%$, e em 2013 , com números inferiores a $50 \%$. Esses percentuais têm sido alavancados pelo uso de aparelhos de celulares e smartphones para a conexão digital (IBGE, 2016). Além da ampliação do acesso, os usos da internet têm sido modificados com a centralidade das plataformas de rede sociais, as quais criam novas formas de relação social, de identificação e de subjetivação, a partir de como as pessoas com elas também se engajam (VAN DIJCK, 2016).

Débora Leitão e Laura Gomes (2018) abordaram como as plataformas digitais têm se tornado, a partir de formatos e experiências muito distintas, um espaço de experimentação de si, dando lugar a processos de identificação e experimentação não normativos, o que se verifica de forma específica em relação a pessoas trans e aos processos de transição de gênero (Tayná GENARI, 2017; Simone ÁVILA, 2014). Nancy Baym (2018) aborda como as plataformas de redes sociais modificaram o campo da produção musical, dentre outras características, abrindo espaço para uma miríade de artistas com audiências específicas, ainda que exigindo outras demandas de consumo das próprias plataformas. O que nos interessa é como essas mudanças deram origem a novas representações midiáticas das dissidências de gênero, não mais dependentes dos formatos e restrições normalizantes das emissoras televisivas.

No caso de Linn da Quebrada, suas produções audiovisuais problematizam suas experiências com o corpo, o desejo e também representações hegemônicas que envolvem de forma imbricada questões de gênero, raça e classe. O YouTube permite divulgar suas produções para um público afinado com suas provocações ao mesmo tempo musicais, estéticas e políticas. Para além do seu público, identificamos que Linn também esteve presente em diferentes canais da plataforma, divulgando sua imagem e ideias para além do fragmento de audiência que a acompanha de perto. À medida que seus vídeos se tornaram conhecidos e seu número de seguidores aumentou significativamente nas redes sociais, Linn passou a ser objeto de interesse de outros canais na plataforma e sua dissidência passou a ser seu diferencial.

Em setembro de 2016, Linn da Quebrada foi entrevistada pela jornalista Regina Volpato (2016) para seu canal de mesmo nome no YouTube. Mulher branca, heterossexual e de classe média da sociedade urbana paulistana, ela teve carreira ascendente a partir dos anos de 1990, mas foi como apresentadora do programa de televisão "Casos de Família", no canal de TV aberta Band, no ano de 2004, que ganhou projeção nacional.

Desde o ano de 2016, a ex-apresentadora criou seu canal no YouTube. Nele, por meio de um dos quadros chamado "Prazer, Eu Sou", ela realiza entrevistas com personalidades em emergência nas mídias, com debate sobre diferentes temáticas, desde a importância do amor, sexualidade, migração, moda, música e religião, dentre outros. Transitando entre essas diferenças temáticas, a jornalista entrevistou Linn da Quebrada, aproveitando de seu papel emergente desde a publicização de seus dois primeiros vídeos no YouTube (Enviadescer e Talento). Com a participação da artista, Regina (2016) alcançou seus primeiros 10.000 (dez mil) inscritos em seu canal. ${ }^{5}$ Linn, de outro lado, fez-se conhecida para o público de Regina, ocupando outro espaço para divulgação de seu trabalho artístico.

O vídeo com a participação de Linn no canal de Regina nos permite analisar as negociações performativas de Linn com as mídias. Enquanto ela adentra em espaços midiáticos que the são disponíveis para se fazer conhecer, as próprias mídias remodelam a performatividade de Linn. O cenário da entrevista demonstra que Linn ocupa espaço distinto daquele descrito na análise do videoclipe de "Enviadescer". Naquela oportunidade, Linn caminhava pelas ruas da periferia de uma metrópole urbana. Já na participação no canal de Regina, há novas configurações estéticas, em uma imagem interior que, em vez de buscar contestar uma representação hegemônica de classe social, a reforça, ao reproduzir um cenário comum às classes médias brasileiras.

A cena da entrevista se passa em uma sala pequena e cor-de-rosa. Linn e Regina estão sentadas cada qual em uma poltrona individual de cor verde, trocando olhares mútuos. Ao fundo,

${ }^{5} \mathrm{O}$ vídeo com a participação de Linn da Quebrada é o $5^{\circ}$ de maior popularidade do canal de Regina Volpato. Em ordem de popularidade estão os vídeos: "Vamos falar do que ninguém fala", com 197.509 visualizações, "Ateísmo e religião, com Pirula", com 177.050 visualizações, "Looks da minha vida, com diva depressão", com 157.284 visualizações, e "Gosto de morar sozinha - repensando \#13", com 82.024 visualizações. 
há um piano marrom, com um vaso de flores em cima, enquanto, à frente delas, constantemente a cadelinha de nome Agatha recebe carinho de Regina e veste uma roupa na qual é possível ler a frase "inscreva-se", em alusão ao canal desta. Linn usa um cabelo com dreads de cor marrom, vestindo sobretudo de mesma cor. O cenário da entrevista produz tanto o enquadramento imagético, no qual a distinção de classe é percebida no piano ostentado ao fundo da gravação, como performances de gênero e que, nesse caso, manifestam-se nos modos como Linn se apresenta para a entrevista; suas roupas, modos de se sentar, gestos com as mãos, maquiagem sob o rosto, cabelo diferenciado em que usa um penteado com dreads. Há, portanto, uma configuração de gênero estilizada (BUTLER, 2017, p. 243) que negocia com representações de classe, gênero e raça. Linn, aqui, aparece em uma imagem feminina, sintonizada com um estilo distinto de moda, contrastando com as vestimentas populares de seu clipe.

No que se refere à entrevista, é interessante notar que Regina Volpato (2016) comenta com suas seguidoras que a conversa será com Linn da Quebrada que, segundo ela, é uma artista "que tem dois clipes que bombam na internet, "Talento" e "Enviadescer". Mas ela é muito mais do que a gente vê nos clipes, e eu nem sei como apresentá-la. Eu não sei como te apresentar, Linn. Você é o quê?". Ao interpelar a artista para que se posicione em termos de identidade, ela está dialogando com seu próprio público, não familiarizado com suas performances dissidentes. A diferença de Linn no programa de entrevistas não a aloca, nesse caso, a um espaço de violência ou de estranheza no qual a corporalidade preta e travesti poderia ser considerada enquanto abjeta, mas a reconhece como uma artista que "bomba", ou seja, que alcança reconhecimento pelas mídias sociais.

Em um contexto no qual a internet "tornou-se a forma predominante de comunicação por toda parte" e, como demonstra Castells (2015), "é o tecido de comunicação de nossas vidas, para o trabalho, para a conexão pessoal, para a formação de redes sociais, para informação, para diversão, para serviços públicos, para a política e até para a religião" (p. 111), a possibilidade ampliada de criação de conteúdo midiático diverso é característica que possibilita que artistas independentes possam se projetar para diferentes públicos, a partir da publicação de suas produções e de sua presença nas plataformas digitais. Característica que é importante para a compreensão de como Linn da Quebrada utiliza essa possibilidade ampliada de comunicação e produção de conteúdo próprio com as mídias digitais, possibilitando que tenha uma visibilidade específica, muito distinta das presenças das travestis na televisão, abordadas no início do texto, na década de 1980. A artista sob análise negocia com as normas de gênero e a produção política da dissidência de forma a se posicionar no contexto político em que se insere.

\section{A produção da dissidência em período de acirramento das políticas de gênero}

A visibilidade alcançada por artistas como Ney Matogrosso, dentre outros citados na abertura deste artigo, deu-se tanto pelas performances andróginas trazidas enquanto novidades dissidentes aos palcos do país, em pleno período de ditadura civil militar, como pela cobertura midiática que os acompanhava. Ainda assim, naquele momento, enquanto expressões dissidentes de gênero, representavam uma ameaça à ordem moral vigente por tencionar 0 regime de visibilidade a partir do qual o gênero e sexualidade eram submetidos a controle. Um regime de visibilidade

[...] traduz uma relação de poder sofisticada, pois não se baseia em proibições diretas, antes em formas indiretas, mas altamente eficientes, de gestão do que é visível e aceitável na vida cotidiana. Assim, um regime de visibilidade é também um regime de conhecimento, pois o que é visível e reconhecido tende a estabelecer as fronteiras do pensável (MISKOLCI, 2017, p. 149).

A dissidência produzida por Linn da Quebrada é tributária de um novo contexto, marcado pela abertura de novas visibilidades para as homossexualidades e dissidências de gênero no Brasil dos últimos anos, com relativo reconhecimento e ganho de direitos e também emergência midiática de performatividades de gênero travestis, transexuais e não binárias. Desde 1997, há um novo regime de visibilidade para essas experiências, que adentram os diferentes canais de mídias, seja a partir do debate sobre direitos humanos envolvendo casamento civil, uso do nome social por travestis e transexuais ou o direito a procedimentos específicos de saúde a partir do Sistema Único de Saúde. Soma-se a ele a expansão da discussão sobre os temas, e de novos processos de identificação e da organização coletiva proporcionada pela internet. Nas palavras de Miskolci:

No Brasil, desde 1997, entramos em um novo regime de visibilidade sexual. Foi nesse ano que o Conselho Federal de Medicina criou a primeira resolução sobre as cirurgias transexualizadoras, disseminou-se o acesso comercial à internet, iniciou-se a distribuição gratuita do coquetel antirretroviral para os portadores do hiv e aconteceu a primeira parada do orgulho LGBT. Cristalizavam-se, assim, as condições para que as homossexualidades e as dissidências 
de gênero - alvo histórico de perseguição, repressão e controle na sociedade brasileira pudessem se tornar, progressivamente, mais visíveis em toda a sua pluralidade (MISKOLCl, 2014, p. 17).

No entanto, em reação à mudança no regime de visibilidade, consolidou-se - desde a última década - uma agenda anti-igualitária que buscou retroagir certos avanços de direitos conquistados (MISKOLCI, Pedro Paulo PEREIRA, 2019). Em parte, o acirramento do debate contra e a favor dos direitos sexuais no Brasil foi também favorecido pela fragmentação das pautas políticas na internet, considerada a dinâmica envolvendo a autocomunicação (CASTELLS, 2015) com as mídias e plataformas de mídias digitais. Com as novas mídias, tanto é incentivado o aumento de visibilidade para determinados grupos historicamente invisibilizados - é o caso da emergência e fortalecimento das identidades trans (Mario CARVALHO; Sérgio CARRARA, 2015) -, como também de grupos que se articularam em torno do combate à chamada "ideologia de gênero", e que se pauta na oposição a políticas educacionais direcionadas à igualdade de gênero e ao respeito às sexualidades não heterossexuais.

Interessa-nos perceber e analisar que é também dentro de um cenário mais amplo de disputas envolvendo categorias tais quais gênero e sexualidade que Linn da Quebrada emergirá enquanto artista. Sua visibilidade conquistada, ainda que para um fragmento da audiência, dimensão caraterística dos usos das mídias contemporâneas, irá também ser disputada com a visibilidade de pautas anti-igualitárias, estas que trazem consigo o ímpeto de perseguição a artistas que tensionam em seus trabalhos as normas de gênero e sexualidade.

No mês de setembro de 2017 , o país foi tomado por discussões a respeito da relação entre censura e visibilidade envolvendo produções artísticas com o tema da diversidade sexual. Isso se deu a partir do cancelamento da exposição "Queermuseu - Cartografias da Diferença na Arte Brasileira", que estava em cartaz há aproximadamente um mês junto ao Santander Cultural, em Porto Alegre/RS. De curadoria do artista plástico Gaudêncio Fidelis, a exposição reunia um acervo com 270 trabalhos artísticos, de 85 artistas nacionais e internacionais, e que abordavam as diferenças de gênero e sexualidade. Ela foi cancelada a partir de intensa mobilização e campanha articulada produzida por meio de plataformas digitais, com destaque para o protagonismo do Movimento Brasil Livre (MBL) e outros grupos de empreendedores morais, responsáveis pela propagação de um pânico moral calcado na suposta ameaça às crianças representada pela exposição, já que, na visão dos referidos grupos, a mesma estava promovendo um incentivo à homossexualidade (BALIEIRO, 2018).

O cancelamento da exposição abriu espaço para a problematização da relação entre arte e política, assim como para a produção dialógica da performatividade de Linn da Quebrada, a partir de engajamentos com as mídias digitais. Em novembro do referido ano, a empresa Vodka Absolut lançou a campanha "Quando a arte resiste, o mundo progride", e que possibilitou a criação de diferentes relações entre Linn, as mídias e a audiência que a acompanha, em ação que fluiu entre o online e o off-line. Produzida em formato audiovisual (LINN DA QUEBRADA feat, 2017), com letra direta contra o preconceito e a transfobia, trazia dados informando que o Brasil é o país que mais mata pessoas transexuais no mundo, segundo publicação da ONG Transgender Europe (TGEU, 2016), e destacava as experiências travestis e transexuais, contando também com a participação das artistas Assucena Assucena e Raquel Virgínia, ambas cantoras da banda "As Bahias e A Cozinha Mineira", e com a participação central de Linn (LINN DA QUEBRADA feat, 2017).

O lançamento da campanha em período de acirramento dos debates envolvendo liberdade artística e censura fez com que perambulássemos pelo Instagram, buscando analisar que relações estavam sendo produzidas com sua audiência. Realizamos esse procedimento após a campanha nos ter demonstrado que os engajamentos de Linn transcendiam sua atuação nas mídias ou com a internet. Foi então possível perceber a relação dialógica com os engajamentos que sua própria audiência opera junto às mídias e ao entorno de sua construção performativa.

O engajamento da audiência, produzindo dialogicamente Linn e sua visibilidade, foi por nós observado quando passamos a seguir a hashtag \#arteresiste. Observamos então os fluxos de relações que passaram a ocorrer a partir da imagem do mural denominado "MURAL RESISTIR E EXISTIR 2017", localizado no Elevado Presidente João Goulart, conhecido popularmente como "Minhocão", na cidade de São Paulo/SP. Grafitado por Patrick Rigon e Renan Ilustrador, o mural é fruto da campanha da já referida empresa, e ele representa, segundo descrição, "uma celebração da resistência diária da comunidade Trans para construir uma sociedade livre, onde todas as pessoas possam ser o que se é" (ABSOLUT VODKA, 2017). No centro do grafite se apresenta a imagem de Linn da Quebrada, ao lado de Assucena Assucena e Raquel Virgínea, dentre outras, acrescida de frases, desenhos e elementos estéticos relacionados à "resistência". Com ele, pessoas variadas passaram a interagir com o mural, tirando fotos de si e postando na plataforma do Instagram, trazendo à tona o debate sobre gênero e sexualidade a partir de questões envolvendo direitos da população trans. Por meio da produção de fotos marcadas 
pela hashtag, também aderiam ao movimento de "arte e resistência", em oposição aos esforços de censura.
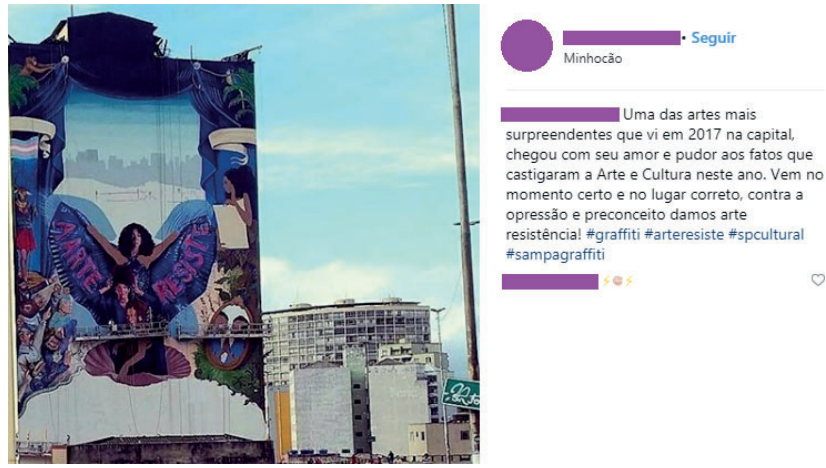

Figura 1 - Imagem do grafite no Minhocão a partir da hashtag \#arteresiste

Fonte: Conteúdo público capturado por print screen, compondo acervo da pesquisa. ${ }^{6}$ \#PraTodoMundoVer A imagem representa um print screen de uma postagem na plataforma do Instagram, realizada por um seguidor de Linn da Quebrada e que utilizou a hashtag \#arteresiste no mês de setembro de 2017. A imagem é dividida em dois planos: no canto esquerdo, é possível ver o grafite, que apresenta Linn da Quebrada com os braços abertos, usando uma capa em que se lê "Arte Resiste"; já no direito, há a frase que acompanha a postagem no Instagram, que refere "Uma das artes mais surpreendentes que vi em 2017 na capital, chegou com seu amor e pudor aos fatos que castigam a Arte e Cultura neste ano. Vem no momento certo e no lugar correto, contra a opressão e preconceito damos arte resistência! \#graffiti \#arteresiste \#spcultural \#sampagraffiti".

Com a perambulação pelos fluxos produzidos pela campanha e que resultaram da hashtag, observamos como as pessoas puderam interagir tanto com o grafite enquanto arte de rua, como, por meio do Instagram, com a produção da Linn. A interação no Instagram com o trabalho de Linn, que investe em demarcar seu corpo negro, periférico, bixa e travesti, também indica como a audiência de Linn reconhece em seu trabalho um compromisso político.

A relação entre Linn e sua audiência se dá em um espaço híbrido: entre as plataformas digitais, os palcos e as ruas, entre a arte e o comprometimento político, entre a resistência política e as dimensões comerciais das mesmas plataformas e, no caso específico, do projeto publicitário da Vodka Absolut. Sua caracterização nos faz refletir sobre qual o alcance da politização nestes termos. Compreendemos a dimensão das representações nas mídias como algo relevante para as disputas políticas do presente, possibilitando que pessoas que não se enquadram nas normas hegemônicas de gênero, sexualidade e raça sejam reconhecidas em sua humanidade e dignidade. Além disso, as plataformas digitais também permitem a formação de redes de apoio, as quais podem ser condensadas em torno do trabalho de artistas como Linn, conforme demonstramos.

De outro lado, também atestamos como, em uma sociedade ultrassegmentada, tais representações circulam em redes restritas, o que diminui bastante o seu potencial transformador. Além disso, as mediações das plataformas digitais não são neutras, são calcadas em valores comerciais cada vez mais arraigados na sociedade contemporânea, como popularidade e protagonismo. Em uma sociedade cada vez mais centrada nas lógicas das plataformas digitais, a visibilidade midiática pode parecer substituir a demanda por transformações substantivas na realidade social. Ao admitir todas essas questões que compõem o contexto e trajetória de Linn, consideramos importante a análise da forma como Linn negocia com as normas nos contextos midiáticos específicos, transcendendo as próprias plataformas digitais, ao participar de programa televisivo.

\section{Do YouTube à teve: entre a dissidência e a celebração da diversidade}

Já tendo seu trabalho reconhecido nas plataformas digitais, Linn participou do programa "Amor \& Sexo",7 da Rede Globo, apresentado por Fernanda Lima, programa que foi ao ar em 02 de março de 2017.

Nessa edição do programa, a temática em discussão estava relacionada a questões LGBT, da cultura à discriminação e à violência. Linn da Quebrada foi uma das convidadas, juntamente com Liniker, Assucena Assucena e Raquel Virgínea, o jornalista Andre Fischer, e a cantora Cibelle, Regis Paulino, e as drag queens Pabllo Vittar, Gloria Groove, Aretuza Lovi e Sarah Mitch, as artistas Alma Negrot, Koichi Sonoda e Vic Haila, dentre muitos outros convidados e convidadas.

\footnotetext{
${ }^{6}$ Durante a pesquisa, foram capturadas mais de 200 imagens em que a audiência de Linn interagiu com a hashtag e o grafite mencionados, e todas estavam disponíveis em sítio público. Para fins de preservar o anonimato das pessoas envolvidas, optamos por suprimir a imagem e o nome dos perfis.

7 "Amor \& Sexo" estreou em agosto de 2009 na televisão, apresentado por Fernanda Lima. Entre seus objetivos, está o de abordar temáticas envolvendo sexo e sexualidade em televisão aberta. O programa analisado está disponível em https://globoplay.globo.com/v/5695481/.
} 
O programa começa apresentando as artistas ao som de marcha carnavalesca sob confetes e, em seguida, a apresentadora Fernanda Lima abre o episódio se posicionando em prol do orgulho LGBT, defendendo o fim da violência e discriminação contra essa população. Apresentado como um "show de diversidade", o episódio é marcado por trazer muitas cores, em um cenário em que a diversidade é enaltecida, e em que o carnaval é o pano de fundo. Esses elementos são construídos seguindo um padrão palatável à televisão, deslocando a "dissidência" à aceitabilidade e à tolerância. Ao fazer referência a um ritual de celebração passageiro, marca da identidade brasileira, apresenta questões das diferenças sob a chave da festividade, relembrando a festa popular na qual as diferenças são enaltecidas para, em seguida, serem novamente marginalizadas.

Linn da Quebrada é uma das convidadas e juradas do programa. Ela nele comparece com um macacão rosa aveludado colado ao corpo e cabelo vermelho avolumado. Nas imagens da cenografia do programa, percebe-se que os elementos estéticos são festivos e "carnavalescos", embora Linn constantemente demonstre uma presença com tom de seriedade, demarcando sua presença contestadora, dentro da estética "carnavalesca" proposta, acentuando sua posição singular. Singularidade esta que aponta para como a produção artística dela destoa do tom do programa.

Durante o programa, Linn posiciona-se de forma séria, politizando o debate sobre as diferenças que é apresentado ora em um tom pedagógico didatizante, ora em tom humorístico. Perto do final, o episódio chega a apresentar o marido da apresentadora, o artista Rodrigo Hilbert, montado como a "drag misteriosa", antes anunciada por todo o programa. De forma a contrastar com o tom humorístico abordado, Linn assume para si a designação "travesti" por sua marginalidade e discute sobre as violências sofridas pelas mulheres trans. Em sua apresentação musical, canta "Bixa Preta", fazendo alusão às mortes de "bixas pretas" no Brasil, ao mesmo tempo em que afirma a resistência dessas mulheres: "Que eu sou uma bixa loka preta favelada, Quicando eu vou passar e ninguém mais vai dar risada, E se tu for esperto, pode logo perceber, Que eu já não de brincadeira, eu vou botar é pra fuder".

O interessante dessa participação de Linn no programa é que ela produz uma nova projeção de sua carreira, ainda que tensionando com seu próprio público. Em sua plataforma do Instagram, a imagem com maiores reações de públicos, desde comentários e curtidas, no decorrer do ano de 2016 até o início do ano de 2017, é de sua participação no programa. Em sua página no Facebook, o compartilhamento de uma foto em que performa junto de Liniker no palco de "Amor \& Sexo" foi a publicação de maior número de reações em sua página no mês de março daquele ano, somando 4413 (quatro mil e quatrocentos e treze) reações, sendo dessas 1730 (um mil e setecentos e trinta) por meio da reação "amei" disponível na plataforma. O alcance de sua participação aponta para a relação aproximada entre artistas e suas audiências, em convergência entre as mídias digitais e televisiva. Interessante notar é que a interação de seu público, comentando sua participação no programa televisivo, nem sempre é positiva. Decorrente do tom, avaliado como pouco politizado do programa, e em razão de sua presença na emissora, criticada por muitos de seus seguidores por sua presumida orientação política contrária a governos progressistas, foi alvo de intensas críticas advindas de sua própria audiência.

A despeito das críticas, ampliou sua audiência. Na era digital, Linn pôde se tornar uma cantora com reconhecimento crescente, algo provavelmente impossível no cenário centralizador da era das mídias massivas analógicas. Para tanto, construiu sua carreira a partir de seus engajamentos performativos com as mídias, e, dentro delas, os canais, os programas, as plataformas, ressaltando ou negociando sua dissidência das normas ao se identificar como travesti, bixa, preta e "da quebrada".

\section{Consideraçōes finais}

Utilizando-se das plataformas de mídias digitais, Linn da Quebrada divulgou suas produções audiovisuais e passou a interagir com um público cada vez mais amplo. Com essa visibilidade, conquistada a partir de engajamentos performativos produzidos com as plataformas de mídias digitais e em convergência com outros meios de comunicação, pôde expressar, em forma de narrativas líricas, visuais e estéticas, sua dissidência em termos de gênero e sexualidade. Analisamos como essa dissidência se apresentou de forma estrategicamente negociada, na medida em que sua performatividade se constituiu em uma relação dialógica com os públicos e as diversas mídias em que atuou.

Sua carreira em ascensão nos permitiu analisar e desvelar as modificações presentes na produção de relações entre artistas, as mídias e sua audiência, dentro de uma configuração midiática altamente segmentada que deu espaço para novas representações midiáticas de afronta às normas restritivas, hierarquizadoras e moralizantes de gênero, sexualidade e raça. A dissidência e o afrontamento das normas que não são, contudo, os únicos elementos presentes 
na sua construção performativa. Reconhecemos que há uma relação dialógica entre a performance da artista e as mídias e plataformas digitais de que fez uso, considerando que as últimas não são apenas o cenário para suas performances, mas também atuam na própria produção de Linn.

Em sua produção artística e audiovisual na era da convergência midiática, Linn mantém sua audiência cativa e crescente nas redes sociais, alimentada de forma frequente por suas performances de palco e seu cotidiano. Recentemente, transformou-se em apresentadora de televisão, junto com Jup do Bairro, em junho de 2019, no programa "TransMissão", no Canal Brasil, programa este dirigido por Claudia Priscila e Kiko Goifman, diretores do filme "Bixa Travesti" (2018).

\section{Referências}

ABSOLUTVODKA.AbsolutArtResistance, 23/1 1/2017. Disponívelem https://www.absolutartresistance. com.br/. Acesso em 06/08/2019.

ÁVILA, Simone. Transmasculinidades: A emergência de novas identidades políticas e sociais. 1. ed. Rio de Janeiro: Simmer \& Amorim Edição e Comunicação Ltda., 2014.

BALIEIRO, Fernando de Figueiredo. "'Não se meta com meus filhos': a construção do pânico moral da criança sob ameaça". Cadernos Pagu, n. 53, 2018. Disponível em http://www.scielo.br/ scielo.php?script $=$ sci_abstract\&pid $=$ S0104-83332018000200406\&lng $=$ pt\&nrm $=$ iso. Acesso em 29/01/2019.

BAYM, Nancy K. Playing to the crowd: musicians, audiences, and the intimate work of connection. New York: New York University Press, 2018.

BRAH, Avtar. "Diferença, Diversidade, Diferenciação". Cadernos Pagu, Campinas, Núcleo de Estudos de Gênero Pagu, n. 26, p. 329-376, 2006.

BUTLER, Judith. Problemas de gênero: feminismo e subversão da identidade. Tradução de Renato Aguiar. 13. ed. Rio de Janeiro: Civilização Brasileira, 2017.

CARVALHO, Mario Felipe de Lima; CARRARA, Sérgio. "Ciberativismo trans: considerações sobre uma nova geração militante". Contemporânea, comunicação e cultura, v. 13, n. 2, p. 382-400, maio/ago. 2015. Disponível em https://portalseer.ufba.br/index.php/contemporaneaposcom/ article/view/13865. Acesso em 06/08/2019.

CASTELLS, Manuel. O poder da comunicação. Rio de Janeiro: Paz e Terra, 2015. (cap. 2)

COLLING, Leandro. "A emergência dos artivismos das dissidências sexuais e de gênero no Brasil da atualidade". Revista Sala Preta, v. 18, n. 1, 2018. Disponível em http://www.revistas.usp.br/ salapreta/article/view/125684. Acesso em 06/08/2019.

COLLING, Leandro; SOUZA, Alexandre Nunes de; SENA, Francisco Soares. "Enviadescer para produzir interseccionalidades". In: OLIVEIRA, João Manuel de; AMÂNCIO, Lígia. Gêneros e Sexualidades: Interseções e Tangentes. Lisboa: Centro de Investigação e Intervenção Social, 2017. p. 193-214.

GENARI, Tayná Ribeiro. Processos de Identificação de gênero e Transexualidades na Era das mídias digitais. 2017. Mestrado (Programa de Pós-Graduação em Sociologia) - Universidade Federal de São Carlos, São Carlos, SP, Brasil.

GLOBO PLAY. Amor \& Sexo, 02/03/2017. Disponível em https://globoplay.globo.com/v/5695481/. Acesso em 10/01/2019.

IBGE. INSTITUTO BRASILEIRO DE GEOGRAFIA E ESTATÍSTICA. Pesquisa Nacional por Amostra de Domicílios. Rio de Janeiro, 2015. Disponível em https://biblioteca.ibge.gov.br/visualizacao/livros/ liv98887.pdf. Acesso em 07/01/2019.

IBGE. INSTITUTO BRASILEIRO DE GEOGRAFIA E ESTATÍSTICA. Pesquisa Nacional por Amostra de Domicílios, com foco para Acesso à Internet e à Televisão e Posse de Telefone Móvel Celular Para uso Pessoal. Rio de Janeiro, 2016. Disponível em https://biblioteca.ibge.gov.br/visualizacao/ livros/liv99054.pdf. Acesso em 07/01/2019.

IBGE. INSTITUTO BRASILEIRO DE GEOGRAFIA E ESTATÍSTICA. Pesquisa Nacional por Amostra de Domicílios Contínua. Rio de Janeiro, 2017. Disponível em https://ww2.ibge.gov.br/home/ estatistica/pesquisas/pesquisa_resultados.php?id_pesquisa=149. Acesso em 07/01/2019. 
LEITÃO, Débora Krishke; GOMES, Laura Graziela. "Gênero, sexualidade e experimentação de si em plataformas digitais on-line". Civitas, Porto Alegre, v. 18, n. 1, p. 171-186, jan.-abr. 2018. Disponível em http://www.scielo.br/pdf/civitas/v18n1/1519-6089-civitas-18-01-0171.pdf. Acesso em 14/04/2018.

LEITÃO, Débora Krishke; GOMES, Laura Graziela. "Ełnografia em ambientes digitais: perambulações, acompanhamentos e imersões". Revista Antropolítica, Niterói, n. 42, p. 41-65, 2017. Disponível em http://www.revistas.uff.br/index.php/antropolitica/article/view/546. Acesso em 06/07/2019.

LEITE JUNIOR, Jorge. "Nossos corpos também mudam”: Sexo, gênero e a invenção das categorias "Travesti" e "Transexual" no discurso científico. 2008. Doutorado (Programa de Pós-Graduação em Ciências Sociais) - Pontifícia Universidade Católica, São Paulo, SP, Brasil. Disponível em https:// tede2.pucsp.br/bitstream/handle/3992/1/Jorge\%20Leite\%20Junior.pdf. Acesso em 28/04/2018.

LEITE JUNIOR, Jorge. "Travestis brasileiras e exotismo sexual". Ciências Sociais Unisinos, São Leopoldo, v. 50, n. 1, p. 41-47, jan./abr. 2014.

LINN DA QUEBRADA feat. "As Bahias e a Cozinha Mineira, Absolutas". YouTube, 24/1 1/2017 (3m33s). Disponível em https://www.youtube.com/watch?v=uunqc97qexU. Acesso em 06/08/2019.

LINN DA QUEBRADA. "MC Linn da Quebrada - Enviadescer - Clipe Oficial”. YouTube, 25/05/2016 (2m54s). Direção: Isabela Ribeiro, John Halles e Thiago Felix. Produção: Thiago Felix, Verônica Vieira, Luciana Rabassallo e Sentidos Produções. Disponível em https://www.youtube.com/ watch?v=sazywhOFuEY. Acesso em 05/07/2019.

MISKOLCI, Richard; PEREIRA, Pedro Paulo Gomes. "Educação e Saúde em disputa: movimentos anti-igualitários e políticas públicas". Interface (Botucatu. Online), v. 23, e180353-14, 2019.

MISKOLCI, Richard. "Prefácio". In: ÁVILA, Simone. Transmasculinidades: A emergência de novas identidades políticas e sociais. 1. ed. Rio de Janeiro: Simmer \& Amorim Edição e Comunicação Ltda., 2014.

MISKOLCI, Richard. "Sociologia Digital: notas sobre pesquisa na era da conectividade". Contemporânea, v. 6, n. 2, p. 275-297, jul.-dez. 2016. Disponível em http://www.contemporanea. ufscar.br/index.php/contemporanea/article/view/525. Acesso em 06/08/2019.

MISKOLCI, Richard. Desejos digitais: uma análise sociológica da busca por parceiros on-line. 1 ed. Belo Horizonte: Autêntica, 2017.

MISKOLCI, Richard; BALIEIRO, Fernando de Figueiredo. "Sociologia Digital: balanço provisório e desafios". Revista Brasileira de Sociologia, v. 06, n. 12, jan./abr. 2018. Disponível em http://www. sbsociologia.com.br/rbsociologia/index.php/rbs/article/view/352. Acesso em 06/08/2019.

NEXO JORNAL. "A música e os corpos políticos com Linn da Quebrada". YouTube, 17/05/2018 (1 1 m42s). Disponível em https://www.youtube.com/watch?v=W170olmPFV4\&t=189s. Acesso em $02 / 07 / 2019$.

PATRICIO, Maria Cecília. "No Truque: fluxos migratórios de travestis brasileiras à Espanha sob uma perspectiva transnacional". Carta Internacional, 2009.

PELÚCIO, Larissa. “'Toda Quebrada na Plástica': Corporalidade e construção de gênero entre travestis paulistas". Campos, v. 6, p. 97-112, jan./fev. 2005.

PELÚCIO, Larissa. Abjeção e desejo: uma etnografia travesti sobre o modelo preventivo de aids. São Paulo: Annablume; Fapesp, 2009.

PELÚCIO, Larissa. "Desejos, brasilidades e segredos: o negócio do sexo na relação entre clientela espanhola e travestis brasileiras". Bagoas, n. 06, p. 243-266, 2011 a.

PELÚCIO, Larissa. "Próteses, desejos e glamour: tecnologias de si na construção de corpos travestis no mercado do sexo transnacional”. In: SANTOS, Luís Henrique Sacchi dos; RIBEIRO, Paula Regina Costa (Orgs.). Corpo, gênero e sexualidade: instâncias e práticas de produção nas políticas da própria vida. Rio Grande: EDFURG, 2011b. p. 77-86.

QUEIROZ, Flávio de Araújo. Ney Matogrosso: sentimento contramão, transgressão e autonomia artística. 2009. Doutorado (Programa de Pós-Graduação em Sociologia) - Universidade Federal do Ceará, Fortaleza, CE, Brasil. 
REGINA VOLPATO. "Ser bixa preta e enviadescer / Prazer, eu sou Mc Linn da Quebrada!" YouTube, 06/09/2016 (1 1 m51s). Disponível em https://www.youtube.com/watch?v=jBEKL9InYGA. Acesso em 05/07/2019.

SOLIVA, Thiago Barcelos. "Sobre o talento de ser fabulosa: os 'shows de travestis' e a invenção da 'travesti profissional'”. Cadernos Pagu, n. 53, 2018. Disponível em http://www.scielo.br/pdf/cpa/ n53/1809-4449-cpa-18094449201800530014.pdf. Acesso em 06/08/2019.

SOUZA, Patrick Borges Ramires de. Bixa, Preta, Trans e Periférica: Linn da Quebrada e as performatividades de gênero dissidentes com as mídias digitais. 2019. Mestrado (Programa de Pós-Graduação em Ciências Sociais) - Universidade Federal de Santa Maria, Santa Maria, RS, Brasil.

TEIXEIRA, Flávia do Bonsucesso. "L'ltalia dei Divieti: entre o sonho de ser europeia e o badalo da prostituição". Cadernos Pagu, n. 31, p. 275-308, jul./dez. 2008. Disponível em http://www.scielo. br/pdf/cpa/n31/n31a13.pdf. Acesso em 06/08/2019.

TGEU. TRANSGENDER EUROPE. "TMM annual report". TVT Publication Series, Berlin, v. 14, 2016. Disponível em https://transrespect.org/wp-content/uploads/2016/1 1/TvT-PS-Vol14-2016.pdf. Acesso em 08/02/2019.

VAN DIJCK, José. La cultura de la conectividad. Buenos Aires: Siglo Veintiuno Editores, 2016.

Patrick Borges Ramires de Souza (borgespsouza@gmail.com) é mestre em Ciências Sociais pela Universidade Federal de Santa Maria (UFSM). É bacharel em Direito formado pela Universidade Regional Integrada, campus Santiago, e mestre em Ciências Sociais pela Universidade Federal de Santa Maria. Integrou, entre os anos de 2016 a 2018, o Coletivo VOE de Diversidade Sexual, e desde 2017 é integrante do NEERD (Núcleo de Estudos em Emoções e Realidades Digitais). Atualmente, é doutorando em Ciências Sociais pelo Programa de PósGraduação em Ciências Sociais da Universidade Estadual de Campinas (Unicamp).

Fernando de Figueiredo Balieiro (fernandofbalieiro@gmail.com) é doutor e Professor Adjunto do Departamento e do Programa de Pós-Graduação em Ciências Sociais da Universidade Federal de Santa Maria (UFSM). É autor de artigos e livros voltados às mídias e às diferenças em perspectiva sociológica afinada com os estudos culturais. Atualmente, é um dos coordenadores do GT de Sociologia Digital do Congresso Brasileiro de Sociologia. 
COMO CITAR ESTE ARTIGO DE ACORDO COM AS NORMAS DA REVISTA

SOUZA, Patrick Borges Ramires de; BALIEIRO, Fernando de Figueiredo. "Linn da Quebrada e os engajamentos performativos com as mídias digitais: uma análise sociológica de uma trajetória artística dissidente de gênero". Revista Estudos Feministas, Florianópolis, v. 29, n. 2, e67834, 2021.

\section{CONTRIBUIÇĀO DE AUTORIA}

Patrick Borges Ramires de Souza: Concepção, coleta e análise de dados, elaboração do manuscrito, redação, discussão dos resultados, revisão e aprovação da versão final do trabalho.

Fernando de Figueiredo Balieiro: Concepção, análise de dados, elaboração do manuscrito, redação, discussão dos resultados, revisão e aprovação da versão final do trabalho.

\section{FINANCIAMENTO}

O presente trabalho foi realizado com apoio da Coordenação de Aperfeiçoamento de Pessoal de Nível Superior - Brasil (CAPES) - Código de Financiamento 001.

\section{CONSENTIMENTO DE USO DE IMAGEM}

Não se aplica.

\section{APROVAÇÃO DE COMITÊ DE ÉTICA EM PESQUISA}

Não se aplica.

\section{CONFLITO DE INTERESSES}

Não se aplica.

\section{LICENÇA DE USO}

Este artigo está licenciado sob a Licença Creative Commons CC-BY 4.0 International. Com essa licença você pode compartilhar, adaptar, criar para qualquer fim, desde que atribua a autoria da obra.

\section{HISTÓRICO}

Recebido em 30/09/2019

Reapresentado em 11/05/2020

Reapresentado em 29/05/2020

Aprovado em 18/06/2020 